ESJ Social Sciences

\title{
Examining the Theme: A Healthy Work Place and its Role in Promoting Work Place Health
}

\author{
Flourish Itulua Abumere, DPHA Candidate, MA, MRS, BSc \\ University of Central Nicaragua, Nicaragua
}

Doi:10.19044/esj.2021.v17n32p58

Submitted: 31 July 2021

Accepted: 23 August 2021

Published: 30 September 2021
Copyright 2021 Author(s)

Under Creative Commons BY-NC-ND

4.0 OPEN ACCESS

Cite As:

Abumere F.I. (2021). Examining the Theme: A Healthy Work Place and tts Role in Promoting Work Place Health. European Scientific Journal, ESJ, 17 (32), 58.

https://doi.org/10.19044/esj.2021.v17n32p58

\begin{abstract}
Workplace health promotion initiatives that aim to improve employees' health and fitness have steadily increased throughout time. Previous studies have looked at the effectiveness, cost-effectiveness, and barriers to participating in workplace health promotion. The number of studies supporting the effectiveness of workplace health promotion in improving employees' health and well-being through changing their health behaviors is rising. This paper focuses on the importance of workplace health promotion in assuring employees' general well-being and the relevance of these perspectives in dealing with workplace illness prevention.
\end{abstract}

Keywords: Workplace, Health, Promotion, disease prevention

\section{Introduction}

Hundreds of millions of workers across the globe are concerned about their health, stability, and well-being. However, the problem affects more than just people and their families. It is critical for businesses, communities, and national and international economies (WHO, 2010). Economic prosperity and population health both need a healthy and productive workforce. The total amount of products and services acquired by a group of employees in a given period is known as workforce productivity (Ramirez \& Nembhard, 2004). It is one of many kinds of productivity measured by economists. Workforce productivity, also known as labour productivity, is a metric used to assess an organization, a process, an industry, or a given nation. Employee productivity, 
on the other hand, is a way of measurement used at the individual level, built on the hypothesis that overall performance can be segmented into progressively smaller units until (Mora et al., 2020), eventually, to the individual employee, for the motive of granting a benefit or sanction based on individual performance (OECD Manual, 2001; Schreyer \& Zinni, 2020).

Due to the enormous user base and the impact on all aspects of an individual's health, the World Health Organization has emphasized the workplace as a site for health promotion. Workplace health promotion is the effort of organizations, workers, society at large, and even the government to enhance people's mental and physical health and well-being at the worksite. The phrase "workplace health promotion" refers to a thorough examination and planning of human and organizational work levels to strategically develop and enhance a company's health resources. For example, let us acknowledge this instance, Decades ago, employees used to work in settings where smoking was acceptable and doing exercise such as jogging during office hours was unthinkable. Employers would not have considered urging workers to stop eating meat or advice on regular exercise and quit smoking back then. Nevertheless, during the past 30 years, companies' involvement with their workers' health and lifestyle has gained popularity and is now widely accepted (Goetzel et al., 2014).

This contemporary situation is partially attributable to an ageing workforce, which stresses the need for sustainable employment, and, in part, to a better understanding of the role of behavior in health status. As a result, workplace health promotion programs (WHPP) are becoming widespread and acceptable even though the kinds of intervention and design differ (Mattke et al., 2013). Personal and societal standards of behavior and ethics, according to WHO, are at the heart of every major religion and moral system. Causing no harm to others is one of the most fundamental, generally recognized ethical precepts. In the workplace, this entails safeguarding the health and safety of workers (WHO, 2010).

A plethora of evidence shows that businesses that nurture, encourage, and safeguard employees' health are the most prosperous and productive in the long run and have higher employee engagement and retention. Employers must weigh the cost of prevention against the cost of accidents, the financial implications of legal breaches of health, safety, and occupational regulations and laws, and the importance of employees' health as a valuable corporate asset. Compliance with these standards reduces unneeded sick leave and disability, lowers medical expenses and costs combined with excessive turnover, such as learning and continuous development, and boosts long-term efficiency of production of goods or services expressed by some measure and product quality (WHO, 2010). 
It is important to note that organizations that refuse to support healthy workplaces knowingly or unknowingly automatically expose workers, their families, and the general public to unnecessary danger and human misery (Schnall, 2018). Furthermore, their businesses and administrations may face expensive lawsuits under national or international labour regulations. Managers and directors who face trial and are convicted of breaches may face penalties or even prosecution ( $\mathrm{Li} \&$ Singleton, 2019). Multinational corporations that attempt to reduce worker's health and safety costs by relocating their most hazardous industrial processes to countries with weaker health, safety, and labour legislation or enforcement may find that their companies and products may become the subject of substantial international public attention and media scrutiny, jeopardizing their capital flows and financial performance (Ruggie, 2013; Reese, 2018).

\section{A Healthy Workplace}

The World Health Organization defined health as "a state of complete physical, mental, and social well-being, and not merely the absence of disease" (World Health Organization, 2006; Kuhn \& Rieger, 2017). In alignment with this, the term "healthy workplace" proposed during the WHO consultation process states that a healthy workplace is one in which workers and managers work collaboratively to use best practices to ensure, safeguard, and promote the health, safety, and well-being of all working people, as well as the conservation of the workplace (Schulte et al., 2015; Jensen \& Van der Voordt, 2019), by taking into account the following supported by available data:

- Health and safety concerns in the physical work environment (Kortum, 2014).

- Health, safety and well-being concerns in the psycho-social work environment, including organization of work and workplace culture (Burke, 2019; Zhu et al., 2020)

- Personal health resources in the workplace (Chen \& Fellenz, 2020)

- Ways of participating in the community to improve the health of workers, their families, and other members of the community (Fetherman et al., 2021)

This concept shows how workplace health has progressed from a nearexclusive emphasis on the physical work environment to including psychological and personal health-related variables. Not just to avoid workplace harm but also to evaluate and enhance people's general health, the workplace has become a successful venue for promoting health and preventive health practices (Kim, 2016). Workplaces that are friendly and accommodating to older employees, individuals with chronic illnesses or impairments, or workers with visible limitations are becoming more of a 
priority (Chrodis, 2016; Pransky et al., 2016). Employment provides enhanced self-esteem, stability, responsibility, and independence, in addition to income, which is the primary reason most individuals work. Increased employment and higher earnings may be linked to getting hired and gaining that highly soughtafter experience (Kalleberg, 2011). Working, on the other hand, has specific negative impacts. Work-related injuries are a potential. Furthermore, working long hours is sometimes linked to a lack of sleep and exercise (Lim et al., 2016). A healthy workplace can help to mitigate the adverse effects of labour.

\section{Healthy Workplace Processes and Avenues of Influence}

To establish a healthy workplace, an organization must examine the avenues or spheres of influence where actions should aim and the most effective methods through which employers and employees can act. According to the model presented below, four main areas may be mobilized or affected by healthy workplace efforts, created via comprehensive research and expert evaluation (Burton \& WHO, 2010).

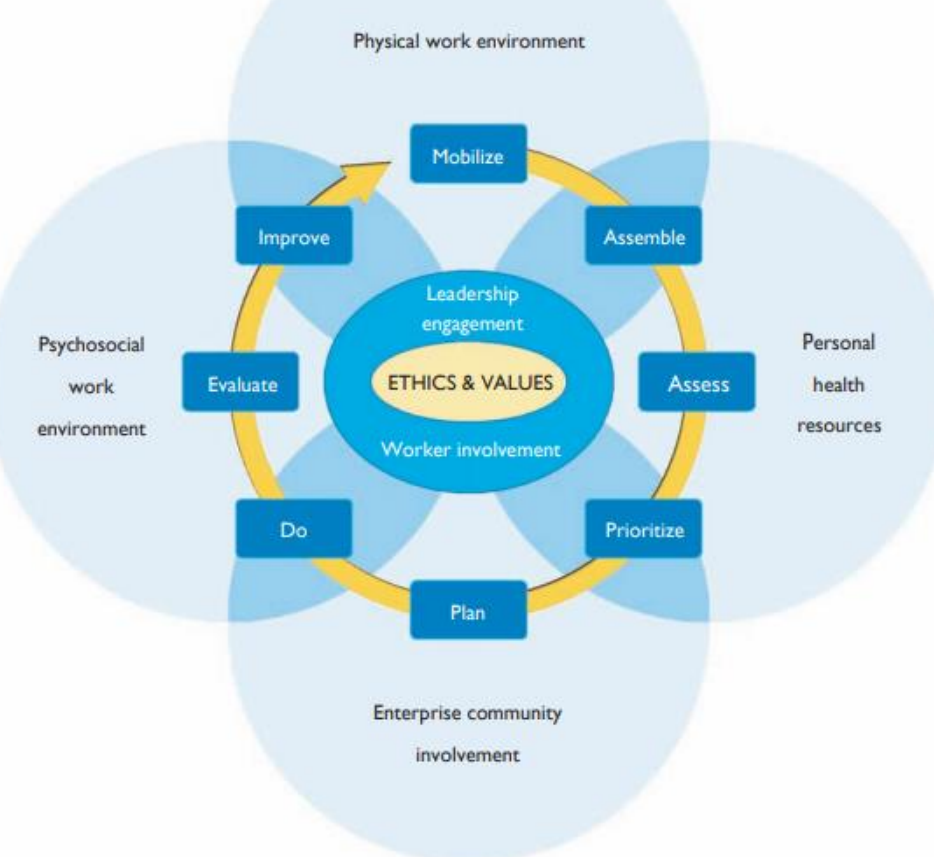

Figure 1.

(Cited in Healthy workplaces: a model for action. WHO, 2010)

The model's key process features include a focus on step-by-step 'continual' mobilization procedures and worker engagement. There is a standard set of ethics and values as seen in the figure above. The figure's 
overlapping circles represent the four areas where activities toward a healthy workplace may be best conducted. As the figure's overlapping circles indicate, routes of influence frequently overlap with one another (Burton \& WHO, 2010).

The Physical Work Environment: The physical work environment includes buildings, the environment, equipment, furnishings, goods, chemicals, supplies, and manufacturing processes (Loftness et al., 2007). These risk factors may impair employees' physical and emotional well-being. In work environments in which employees execute activities in automobiles and places outside the workplace, environmental hazards usually have tremendous potential to cripple or kill employees. Therefore, early legislation and regulations can address these issues (Pettigrew et al., 2018). Also, it is essential to note that work-related dangers, both in developed and developing nations, endanger employees' lives every day (Campbell \& Price, 2016). Hazardous waste such as solvents, physical hazards (noise, radiation, vibration), extreme temperatures, biological hazards (e.g., hepatitis B, malaria), ergonomic hazards (e.g., processes requiring excessive force, awkward posture), mechanical hazards (e.g., machine hazards related to nip points, cranes, forklifts), and energy hazards are some typical problems employees face in organizations relating to physical hazards in their environment (Jayaraj et al., 2019).

The Psychosocial Work Environment: Organizational culture and attitudes, values, beliefs, and everyday activities in the workplace all have an impact on workers' emotional and physical well-being (Dimitrios \& Konstantinos, 2014). Factors that may create emotional or mental stress in the workplace are known as stressors (Quick \& Konstantinos, 2014). Poor work organization, poor organizational culture, lack of policies and practices related to dignity and respect for all workers, harassment and bullying, gender discrimination, stigmatization due to HIV status, intolerance for ethnic or religious diversity, and lack of support for healthy living are all typical examples of psychosocial hazards (Täuber et al., 2018). In contrast to physical job risks, psychosocial hazards are usually discovered and evaluated via surveys or interviews. To address the hazards identified, a power structure of controls would be implemented, including eliminating or modifying them at the source, allocating work to reduce over-workload, removing or retraining supervisors in communication and leadership skills, and enforcing disciplinary actions for workplace harassment, prejudice, and bullying. Enabling flexibility in dealing with work-life conflict situations and allowing flexibility at a work location, including prompt, open, and honest communication can drastically reduce the effect on employees. Workers may be protected by increasing awareness and 
giving training such as in dispute resolution or misconduct cases (Hill et al., 2010).

Personal Health Resources in the Workplace: Personal health resources are access to healthcare, relevant data, tools, possibilities, adaptability, and other healthy relationships that an organization provides to employees to help them optimize or develop better personal lifestyles and monitor and support their physical and mental health (Burton \& WHO, 2010; Schulte \& Verkuil, 2015). Personal health resource problems in the workplace can range from workers finding it challenging to adopt or maintain healthy lifestyles due to work circumstances or a lack of information. For example, long work hours, the expense of exercise facilities or equipment, and a lack of flexibility in when and how long breaks may be taken can contribute to physical inactivity. Poor eating habits may be caused by a lack of nutritious snacks or meals at work, a lack of time to eat, a lack of refrigeration to keep healthy foods, or a lack of awareness. Tobacco use may be permitted or encouraged in the workplace. As a result of the lack of accessible and expensive primary health care, illnesses may go undetected and untreated. High levels of HIV infection may arise from a lack of awareness or resources for HIV/AIDS prevention. Medical services, information, training, financial assistance, facilities, capacity development, versatility, and promotional programs are examples of improving workplace personal health resources and inspiring employees to adopt healthy living habits (Hull \& Pasquale, 2018).

Enterprise Community Involvement: Enterprises have an incredible effect on and are affected by the communities in which they operate. The physical and social environment of the wider community, for example, has a significant impact on the health of workers (Pandita, 2012). The activities in which a business may participate, or the knowledge and resources it might offer to promote the social and physical well-being of a community in which it works, are referred to as enterprise community involvement. This covers elements that influence employees' physical and mental health and their safety and wellbeing. Here are some examples of how businesses may become engaged in their communities. The company may decide to offer assistance and resources by starting efforts to reduce pollution emissions, cleaning up manufacturing processes, or addressing contaminated air and water sources in the community as a whole, supporting community-based HIV testing and treatment for TB, hepatitis, and other common illnesses.

Providing employees and their families with free or subsidized primary health care is a great asset. These may help groups who might otherwise be unable to obtain information. Even though it is not legally necessary, instituting gender equality rules in the workplace to safeguard and assist 
women or protective measures for other vulnerable groups is a great distinction for any business or organization. Enterprise initiatives in a community may make a significant difference for more vulnerable sectors of the enterprise's workforce or community residents in a country or state with universal health care and compelling, possibly the best legislation related to health, hygiene, pollution emissions, and human rights. In a situation where access to healthcare is scarce and labour and environmental regulations are woefully inadequate, its community engagement may significantly impact its community's environmental health and the quality of life of its workers and their families.

\section{Workplace Health Promotion (WHP) - Definition}

In many cases, the act of creating a healthy work environment is just as important as the quality (Sanders et al., 2013). The WHO model is based on a well-known workplace health promotion (WHP) definition by the European Network for Workplace Health Promotion (ENWHP) as the combined efforts of employers, employees, and society to improve people's health and well-being at work (Masanotti \& Briziarelli, 2012; Onyezere, 2020). The Luxembourg Declaration (1997), developed by ENWHP members, serves as the foundation for this definition. 'A modern business strategy aimed at avoiding ill health at work (including work-related diseases, accidents, injuries, occupational diseases, and stress) and promoting health-promoting potential and well-being in the workforce,' (ENWHP, 2012) it says. According to the Luxembourg Declaration, this can be accomplished by enhancing work structure and working conditions, increasing active involvement, and supporting personal development.

This generally accepted (European) definition of workplace health promotion is not unique in its scope. Workplace health is "an approach to protecting and enhancing the health of employees that relies and builds upon the efforts of employers to create a supportive management under and upon the efforts of employees to care for their well-being," according to the Health Communication Unit at the University of Toronto's Centre for Health Promotion in 2004 (Jackson et al., 2006). According to the Centers for Disease Control and Prevention, workplace health programs are 'a coordinated and comprehensive set of strategies that include programs, policies, benefits, environmental support, and links to the surrounding community designed to meet the health and safety needs of all employees' (Barbero et al., 2017).

The health-promoting workplace notion is becoming increasingly relevant as more private and public businesses understand that global competitiveness requires a healthy, qualified, and motivated workforce. Ensuring a dynamic balance between customer expectations and organizational aims while supporting employees' skills and health needs can benefit enterprises and work 
organizations in the marketplace. A health-promoting workplace is mandatory for nations' sustainable social and economic development (Nugent et al., 2018). An encouraging aspect of workplace health promotion is so that many groups can participate, and that it does not-and should not-belong to one group alone (Edelman et al., 2017).

Wynne discovered this in 1990 and then applied the five principles of general health promotion defined by WHO in 1984 to a workplace setting. From Wynne's perspective, workplace health promotion is directed at the underlying causes of ill health, combines diverse methods of approach, aims at effective worker participation, and is not primarily a medical activity, but should be part of work organization and working conditions (Masanotti \& Briziarelli, 2012; Kelsey, 2017). Workplace health promotion is related to and overlaps with return-to-work (RTW) programs, focusing on proactive treatments and employment retention (Nichols et al., 2020). The company's guidelines on Return to Work and Reintegration should provide an excellent overview of this holistic approach. On a global scale, institutions that integrate workplace health promotion and return to work offer good practice models and help their employees grow mentally, mainly if these guidelines should be a component of this complete service for businesses and individuals (Reibis et al., 2019).

\section{Commencing and Sustaining a Workplace Health Promotion Programme}

In many cases, the act of creating a healthy work environment is just as important as the quality (Goetzel et al., 2014). The WHO model is based on a well-known proven organizational method known as "continual improvement," which guarantees that health, safety, and well-being programs meet all parties' requirements and are long-term maintainable. According to the notion, any new endeavor is unlikely to be flawless from the outset (Eldredge et al., 2016). The WHO Regional Office for the Western Pacific created the concept of "continual improvement" for occupational health and safety in 1998. Experts and organizations such as the International Labour Organization (ILO) have progressively updated the model to the current version seen in Figure 2. The method is segmented into steps, each of which explains the fundamental concepts (Burton \& WHO, 2010). 


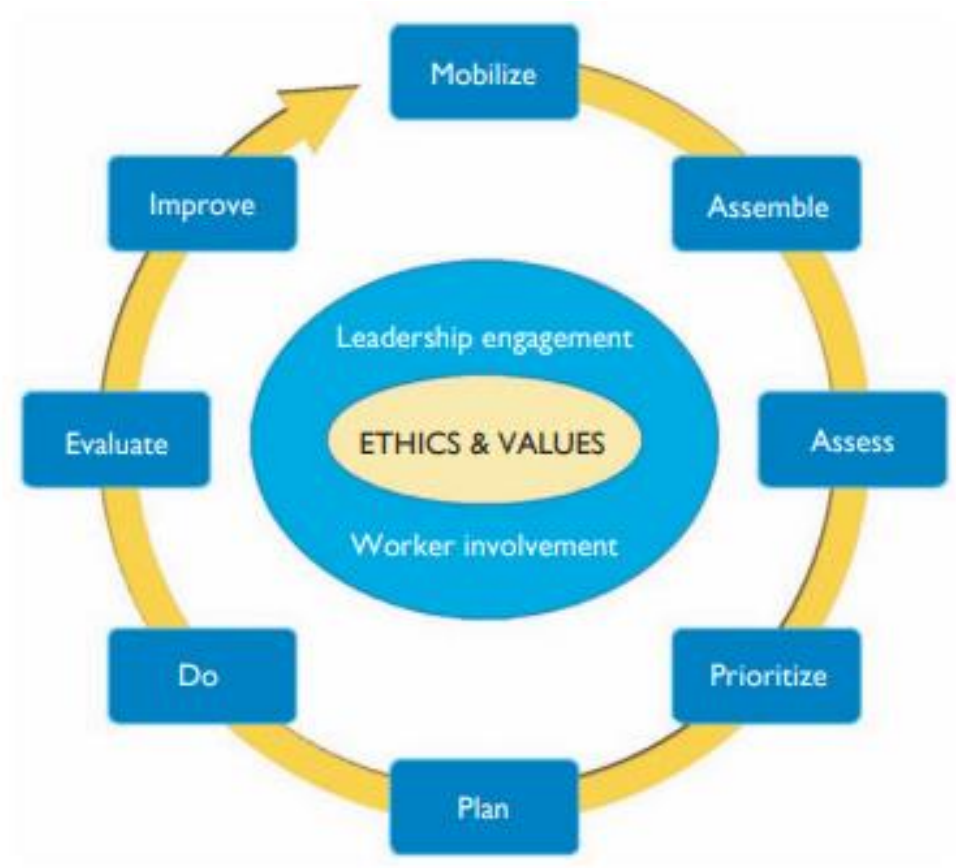

Figure 2. WHO Model of Healthy Workplace Continual Improvement Process.

Mobilize: Mapping people's priorities and needs allows for the successful mobilization of workers and businesses to invest in change. People believe in and act on different ethical standards. Different motivations incite them to action: data, science, reasoning, human tales, compassion, or religious convictions. Knowing who the main opinion leaders and influencers are in an organization is essential to creating momentum behind an activity or project (Burton \& WHO, 2010; Edmund et al., 2020).

Assemble: Once stakeholders have been mobilized, they will show their commitment by forming a healthy workplace team and resources to make a change in the workplace. A previous committee might have taken on this extra responsibility. All enterprise entities, departments, and divisions should sit on the health and safety committee. In joint health and safety committees, employers and employees should be equally represented by any health or safety-oriented staff. The participation of outside consultants or specialists in a small business may be advantageous. For example, a neighborhood occupational health clinic or a big business medical facility may assist (Burton \& WHO, 2010; Lowe, 2020).

Access: The working team that promotes good health begins by assessing the workplace using various tools and metrics, including a list of statistics, questionnaires, and other historical data (if applicable). All of this should be documented. When is the optimum time to do a complete risk 
assessment and hazard identification? Examine current policies and practices concerning the four impact channels. Occupational health data, such as rates of sick leave and workplace accidents and diseases, as well as short-and longterm impairments, rely heavily on workers' health. Another factor to consider is staff health. Find out by conducting a confidential survey or discussing with management, staff, and ideally a health professional. Individual employees should make suggestions for ways to improve their working environment and health and how the company may assist them. It is vital to guarantee that women have equal participation in decision-making and that their problems may be disaggregated while gathering this data (Burton \& WHO, 2010; Jimenez \& Bregenzer, 2018).

Prioritize: Vulnerability to potential work hazards is just one of many factors. Still, specific targets, such as reducing such risks, are critical. Aside from factors such as employee risk, simple solutions such as "quick wins" may motivate and facilitate continued development. The availability of viable solutions, employers' willingness to transform, and other issues related to workplace regulations and politics, choosing to ignore or neglect the problem will unquestionably result in high costs (Burton \& WHO, 2010; Vaughan, 2019).

Plan: After the above mentioned, the next step will be to make a health plan. The company's size and complexity will determine the scale and complexity of the company's strategy. It may focus mainly on the most critical health goals and those that are easily achievable. A 3-5 year strategic plan for a significant firm uses a "big picture" approach with a comprehensive plan that addresses some high-priority issues over such a period. To evaluate performance, the overarching plan should incorporate long-term goals and objectives. Annual plans would be created in order of importance to develop the long-term strategy. When choosing a solution, keep the principle of "learning from others" in mind. Also, keep in mind the four channels of effect when developing solutions. For example, a common mistake is assuming that concerns about the physical work environment such as training or behavior adjustment must necessarily be physical problems. Following approval, it is time to create precise action plans that include goals, expected outcomes, and timelines. With a focus on expanding awareness, it is essential to integrate education and behavioral modification. The necessary funds, facilities, resources, and preparation for launching, marketing, and promoting the program or policy should all be covered. Ensure that the goals and objectives at each step of a strategy or effort are clear and measurable (Burton \& WHO, 2010; Wyatt et al., 2015).

Do: This is the "just do it" stage. Assign each planned activity to a specific actor in the implementation team, and follow-up is necessary (Burton \& WHO, 2010; Jensen \& Van der Voordt, 2019). 
Evaluate: The purpose of an evaluation is to look at the outcomes and figure out why they are what they are. Both the strategy and the outcomes must be evaluated in the short and long term. The viability of the healthy workplace program should be measured over time or after a significant management change. An integrated framework can be obtained by conducting a survey or reviewing current data. Worker health changes cannot be used to explain corporate output or profitability. However, it is critical to keep abreast of these figures and match them to benchmarks (Burton \& WHO, 2010; Di Fabio, 2017).

Improve: All other valuable phases begin right after this step is completed. Changes are based on assessment findings. These modifications may enhance the existing programs or build on the following components. Alternatively, some noteworthy achievements may have been accomplished. Recognizing achievements, appreciating everyone who helped create the successful result, and ensuring all stakeholders are aware of the achievement (Burton \& WHO, 2010; McHugh, 2016).

\section{The Importance of Exercising Workplace Health Promotion}

Health protection and disease prevention initiatives are all vital in the workplace (Tamers et al., 2020). While employers need to provide a safe, hygienic, and hazard-free workplace, they also have several chances to enhance individual health and foster a robust and healthy workplace culture for millions of employee's worldwide (Rongen et al., 2013). Regardless of where you are working, good workplace programs and regulations can lower health risks and increase workers' quality of life. Lowering financial expenditures such as insurance premiums and workers' compensation claims can be achieved by maintaining a healthy staff. Many secondary costs, such as absenteeism and worker productivity, will be reduced as a result. Businesses may strengthen their employees' performance by creating an employee-centered wellness culture (McLellan, 2017). Also, providing supportive conditions where safety is assured and health can develop, and providing access and opportunities for their employers to participate in various workplace health programs. So what are workplace health programs? According to the CDC, when we talk about workplace health programs, we are referring to a coordinated and comprehensive strategic approach that includes training programs, policy and regulation decisions, incentives, behavioral interventions, and connections with surrounding communities that are developed to meet the rules and regulations of all staff members (Koffman et al., 2013).

Among the components and techniques of a workplace health program are:

- Workshops classes on preventive health care which should be accessible to all (CDC, 2016). 
- Local fitness facilities are made available for free (CDC, 2016).

- A tobacco-free workplace policy that promotes healthy behaviors (CDC, 2016).

- Routine health screenings should be covered by employee health insurance (CDC, 2016).

- Create a wholesome workplace setting which can be achieved by taking steps such as providing healthier food or snack options in vending machines or food courts (CDC, 2016).

- Organize a working atmosphere free of known potential hazards, as well as placing solid conditions to identify and handle new issues as they occur (CDC, 2016).

Change can occur at both the personal (i.e., employee) and organizational levels due to workplace health programs. Individually, workplace health initiatives can positively affect an individual employee's health, including their health-related behaviors, health vulnerabilities, and overall lifestyle factors. Workplace health initiatives can have a bearing on healthcare expenses, work attendance, performance, profitability, efficiency, talent acquisition, mindset, and employee motivation and morals for businesses. Employers, employees, families, and communities benefit from disease and injury prevention, safety measures, and long-term health (Schmidt, 2016).

\section{Recommendations}

Employers should be encouraged to improve (or start) health promotion programs by allowing employees and employers to share ideas. Healthy eating, which can be less stressful if taken seriously and sticking to it, is something I advocate. Eat a variety of meals and lots of fruits and vegetables, eat in moderation, and remember that it is better to limit the number of less healthy things in one's diet than to try to remove them entirely (Hull \& Pasquale, 2018).

At all costs, employees, in collaboration with employers, must try to reduce stress at work. There are numerous methods for reducing stress. Firstly, become aware of the things that could stress an employee. Then plan on how to deal with them such as avoiding stressful situations like peak hour traffic: why not find an alternative that could be less stressful? Leaving home before peak traffic begins (Koslowsky, 2013), speaking out if the workload is overbearing when accepting tasks that push the employee beyond the employee's comfort zone-speaking with the boss about any unforeseen circumstances that may become stressful, being aware of the signs and symptoms of stress such as difficulty sleeping or concentrating (Martin et al., 2020). Above all, it is crucial for employees to always pay 
attention to their body's signals and seek medical advice if they have persistent symptoms.

Staying physically active should be encouraged among employees regardless of the size of the organization. On most days of the week, adults should engage in at least 30 minutes of moderate physical activity, as this will unarguably improve their physical and mental well-being and their ability to maintain a healthy weight. Exercise can help avoid cancer, heart disease, and depression (Elsawy \& Higgins, 2010). There are some easy ways to stay active as an employee or even as an employer because the health of everyone in an organization should be of paramount consideration. Firstly, when possible, take the stairs rather than the elevator, walk short distances rather than taking the bus or car, consider cycling to work (Handy et al., 2014), and situate some office tools such as printers some distance away from easy reach (Dewitt et al., 2019). Practicing this will increase the number of steps taken by an employee each day and the number of sports or other physical activities they participate in at work. There are several more ways to increase physical activity including practicing workouts or participating in sports classes.

Small, medium, and large businesses should implement a no-smoking policy (Dony \& Smith, 2017). Smoking tobacco is hazardous to one's health. This isn't just a statement; it's a fact. Tobacco use is the greatest preventable cause of death worldwide. One out of every two long-term smokers, half of whom are in their forties, is killed by tobacco. In the European Union, smoking claims the lives of approximately 650,000 people each year (Aspect Consortium, 2004). There are a slew of additional reasons to quit smoking as well. Generally, the feeling is better as your breathing becomes more regular and healthy. You will gain back tranquility and your warm personality once the nervousness, tension, and restlessness triggered by deciding to quit tobacco die down. You will save financial resources, your skin, hair, teeth, and fingers will look so much healthier, and your breath will be cleaner and you will gain back your position in society as the number of "no smoking" areas increases. On a more pragmatic level, this means that suppressing the impulse to start smoking again will become more challenging (Muraven, 2010).

\section{Conclusion}

When it comes to boosting health and reducing disease and injuries, the workplace can present far more opportunities than expected. Most large and medium-sized businesses, particularly in Western countries, are implementing workplace health programs. When compared to the pace of organizations in developing countries, the situation may be different. Workplace health promotion should be promoted and allowed to grow in its implementation regardless of where our organization operates. The advantages of workplace health promotion cannot be over-emphasized. This 
paper looked at the role of workplace health promotion, how to establish and continue health promotion programs in organizations successfully, and the value of this practice and day-to-day advice that benefits both individuals and groups. To sum up this article, health promotion at work has the potential to impact societal norms, create new sustainable health policies, boost overall healthy behaviors, improve workers' knowledge and abilities, and raise awareness of health screening, immunizations, and vaccinations.

\section{References:}

1. Anual, R. \& Annuale, R. European Agency for Safety and Health at Work.

2. Aspect Consortium (2004). Tobacco or health in the European Union: Past, present and future. Luxembourg: Office for Official Publications of the European Communities

3. Barbero, C., Gilchrist, S., Shantharam, S., Fulmer, E. \& Schooley, M. W. (2017). Doing more with more: how "early" evidence can inform public policies. Public administration review, 77(5), 646

4. Burke, R. J. (2019). Creating psychologically healthy workplaces. In creating psychologically healthy workplaces. Edward Elgar Publishing

5. Burton, J. \& World Health Organization, (2010). WHO Healthy workplace framework and model: Background and supporting literature and practices. World Health Organization

6. Campbell, I. \& Price, R. (2016). Precarious work and precarious workers: Towards an improved conceptualisation. The Economic and Labour Relations Review, 27(3), 314-332

7. CDC Centers for Disease Control and Prevention (2016). Workplace Health Promotion, Workplace Health Model. Division of Population Health, National Center for Chronic Disease Prevention and Health Promotion.

8. Chen, I. S. \& Fellenz, M. R. (2020). Personal resources and personal demands for work engagement: Evidence from employees in the service industry. International Journal of Hospitality Management, 90, 102600

9. Chrodis, J. A. (2016). Companies Promoting Health: Lombardy WHP Network

10. Dewitt, S., Hall, J., Smith, L., Buckley, J. P., Biddle, S. J., Mansfield, L. \& Gardner, B. (2019). Office workers' experiences of attempts to reduce sitting-time: an exploratory, mixed-methods uncontrolled intervention pilot study. BMC public health, 19(1), 1-10 
11. Di Fabio, A. (2017). Positive Healthy Organizations: Promoting wellbeing, meaningfulness, and sustainability in organizations. Frontiers in psychology, 8, 1938

12. Dimitrios, B. \& Konstantinos, V. (2014). Organizational culture and job burnout: A review; International journal of research in Business management, 2(1), 43-62

13. Dony, J. \& Smith, K. (2017, June). Workplace Wellbeing: Bridging Safety and Health. In ASSE Professional Development Conference and Exposition. OnePetro.

14. Edelman, C. L., Mandle, C. L. \& Kudzma, E. C. (2017). Health promotion throughout the life span-e-book. Elsevier Health Sciences

15. Edmund, N. N. K., Linda, A. S. \& Kofi, P. M. (2020). Safety House: A developed Framework to Improve Safety Performance among Highly Risky Industries. International Journal of Environment, Agriculture and Biotechnology, 5, 6

16. Eldredge, L. K. B., Markham, C. M., Ruiter, R. A., Fernández, M. E., Kok, G. \& Parcel, G. S. (2016). Planning health promotion programs: an intervention mapping approach. John Wiley \& Sons

17. Elsawy, B. \& Higgins, K. E. (2010). Physical activity guidelines for older adults. American family physician, 81(1), 55-59

18. ENWHP - European Network for Workplace Health Promotion (2012). The Luxembourg declaration. Retrieved 23 March 2012.

19. Fetherman, D. L., McGrane, T. G. \& Cebrick-Grossman, J. (2021). Health Promotion for Small Workplaces: A Community-Based Participatory Research Partnership. Workplace Health \& Safety, 69(1), 7-14

20. Goetzel, R. Z., Henke, R. M., Tabrizi, M., Pelletier, K. R., Loeppke, R., Ballard, D. W. \& Metz, R. D. (2014). Do workplace health promotion (wellness) programs work?. Journal of Occupational and Environmental Medicine, 56(9), 927-934

21. Handy, S., Van Wee, B. \& Kroesen, M. (2014). Promoting cycling for transport: research needs and challenges. Transport reviews, 34(1), 424.

22. Hill, E. J., Erickson, J. J., Holmes, E. K. \& Ferris, M. (2010). Workplace flexibility, work hours, and work-life conflict: finding an extra day or two Journal of Family Psychology, 24(3), 349.

23. Hull, G. \& Pasquale, F. (2018). Toward a critical theory of corporate wellness. BioSocieties, 13(1), 190-212

24. Jackson, S. F., Perkins, F., Khandor, E., Cordwell, L., Hamann, S. \& Buasai, S. (2006). Integrated health promotion strategies: a contribution to tackling current and future health challenges. Health promotion international, 21(suppl_1), 75-83. 
25. Jayaraj, G., Shah, S. \& Singh, R. (2019). Block-3 Occupational Hazards.

26. Jensen, P. A. \& van der Voordt, T. J. (2019). Healthy workplaces: what we know and what else we need to know. Journal of Corporate Real Estate

27. Jimenez, P. \& Bregenzer, A. (2018). Integration of eHealth tools in the process of workplace health promotion: proposal for design and implementation. Journal of medical Internet research, 20(2), e8769

28. Kalleberg, A. L. (2011). Good jobs, bad jobs: The rise of polarized and precarious employment systems in the United States, 1970s-2000s. Russell Sage Foundation.

29. Karanika, M. (2003). Management of occupational safety and health in the education sector [Fact Sheet 45].

30. Kelsey, C. (2017). Promoting mental health in the workplace

31. Kim, Y., Park, J. \& Park, M. (2016). Creating a culture of prevention in occupational safety and health practice. Safety and health at work, 7(2), 89-96

32. Koffman, D. M. M., Lang, J. E. \& Chosewood, L. C. (2013). CDC resources, tools, and programs for health promotion in the worksite. American journal of health promotion: AJHP, 28(2), TAHP2

33. Kortum, E. (2014). WHO Healthy Workplaces. African Newsletter, 4

34. Koslowsky, M., Kluger, A. N. \& Reich, M. (2013). Commuting stress: Causes, effects, and methods of coping. Springer Science \& Business Media.

35. Kühn, S. \& Rieger, U. M. (2017). Health is a state of complete physical, mental and social well-being and not merely absence of disease or infirmity. Surgery for Obesity and Related Diseases, 13(5), 887

36. Li, L. \& Singleton, P. (2019). The effect of workplace inspections on worker safety. ILR Review, 72(3), 718-748.

37. Lim, A. J., Huang, Z., Chua, S. E., Kramer, M. S. \& Yong, E. L. (2016). Sleep duration, exercise, shift work and polycystic ovarian syndrome-related outcomes in a healthy population: a cross-sectional study. PLoS One, 11(11), e0167048

38. Loftness, V., Hakkinen, B., Adan, O. \& Nevalainen, A. (2007). Elements that contribute to healthy building design. Environmental health perspectives, 115(6), 965-970

39. Lowe, G. (2020). Healthy Change. In Creating Healthy Organizations (pp. 186-216). University of Toronto Press 
40. Manual, O. E. C. D. (2001). Measuring productivity: measurement of aggregate and industry-level productivity growth. Statistics Portal, 1156

41. Martin, J. A., Gheorge, C. E., Molloy, M., O’Halloran, K., Dinan, T. G., Cryan, J. F. \& Clarke, G. (2020). P45 Exercising to control signs and symptoms of stress and depression.

42. Masanotti, G. M. \& Briziarelli, L. (2012). Workplace health promotion in the context of public health. Italian Journal of Public Health, 7(4)

43. Mattke, S., Liu, H., Caloyeras, J., Huang, C. Y., Van Busum, K. R., Khodyakov, D. \& Shier, V. (2013). Workplace wellness programs study. Rand health quarterly, 3(2)

44. McHugh, G. (2016). Measuring dimensions of a healthy workplace climate: A user-friendly assessment tool. International Journal of Disability Management, 11

45. McLellan, R. K. (2017). Work, health, and worker well-being: roles and opportunities for employers. Health affairs, 36(2), 206-213.

46. Mora, Z., Suharyanto, A. \& Yahya, M. (2020). Effect of work safety and work healthy towards employee's productivity in PT. Sisirau Aceh Tamiang. Burns, 2, 1

47. Muraven, M. (2010). Practicing self-control lowers the risk of smoking lapse. Psychology of Addictive Behaviors, 24(3), 446

48. Nichols, A., Geyer, J., Grosz, M., Epstein, Z. \& Wood, M. (2020). Synthesis of Evidence about Stay-at-Work/Return-to-Work (SAW/RTW) and Related Programs. Order, 1605(17-U), 00095

49. Onyezere, J. O. (2020). Health Promotion Activities in Modern Workplace: The Roles of the Employers and Employees. European Journal of Physical Education and Sport Science, 6(7).

50. Pandita, D. (2012). The Essentials of A Healthy Workplace. SAMVAD, 4, 87-92.

51. Pettigrew, S., Fritschi, L. \& Norman, R. (2018). The potential implications of autonomous vehicles in and around the workplace. International journal of environmental research and public health, 15(9), 1876

52. Pransky, G. S., Fassier, J. B., Besen, E., Blanck, P., Ekberg, K., Feuerstein, M. \& Munir, F. (2016). Sustaining work participation across the life course. Journal of occupational rehabilitation, 26(4), 465-479

53. Quick, J. C. \& Henderson, D. F. (2016). Occupational stress: Preventing suffering, enhancing wellbeing. International journal of environmental research and public health, 13(5), 459

54. Ramírez, Y. W. \& Nembhard, D. A. (2004). Measuring knowledge worker productivity: A taxonomy Journal of intellectual capital. 
55. Reese, C. D. (2018). Occupational health and safety management: a practical approach. CRC press

56. Reibis, R., Salzwedel, A., Abreu, A., Corra, U., Davos, C., Doehner, W. \& Secondary Prevention and Rehabilitation of the European Association of Preventive Cardiology (EAPC), (2019). The importance of return to work: How to achieve optimal reintegration in ACS patients. European journal of preventive cardiology, 26(13), 1358-1369

57. Rongen, A., Robroek, S. J., van Lenthe, F. J. \& Burdorf, A. (2013). Workplace health promotion: a meta-analysis of effectiveness. American journal of preventive medicine, 44(4), 406415

58. Ruggie, J. G. (2013). Just business: Multinational corporations and human rights (Norton global ethics series). WW Norton \& Company

59. Sanders, C. L., Krugman, M. \& Schloffman, D. H. (2013). Leading change to create a healthy and satisfying work environment. Nursing administration quarterly, 37(4), 346-355.

60. Sanders, C. L., Krugman, M. \& Schloffman, D. H. (2013). Leading change to create a healthy and satisfying work environment. Nursing administration quarterly, 37(4), 346-355

61. Schmidt, H. (2016). Chronic disease prevention and health promotion. Public health ethics: Cases spanning the globe, 137-176

62. Schnall, P. L., Dobson, M., Rosskam, E. \& Elling, R. H. (2018). Unhealthy work: Causes, consequences, cures. Routledge

63. Schreyer, P. \& Zinni, M. B. (2020). Productivity Measurement, R\&D Assets, and Mark-Ups in OECD Countries. Review of Income and Wealth

64. Schulte, P. A., Guerin, R. J., Schill, A. L., Bhattacharya, A., Cunningham, T. R., Pandalai, S. P. \& Stephenson, C. M. (2015). Considerations for incorporating "well-being" in public policy for workers and workplaces. American journal of public health, 105(8), e31-e44

65. Schulte, V. \& Verkuil, A. H. (2015, May). A toolkit for personal health resources at the workplace. In ICOH 31st International Congress on Occupational Health.

66. Tamers, S. L., Streit, J., Pana-Cryan, R., Ray, T., Syron, L., Flynn, M. A. \& Howard, J. (2020). Envisioning the future of work to safeguard the safety, health, and well-being of the workforce: A perspective from the CDC's National Institute for Occupational Safety and Health. American journal of industrial medicine, 63(12), 1065-1084.

67. Täuber, S., Mulder, L. B. \& Flint, S. W. (2018). The impact of workplace health promotion programs emphasizing individual 
responsibility on weight stigma and discrimination. Frontiers in psychology, 9, 2206

68. World Health Organization (2006). Constitution of the World Health Organization-Basic Documents, Forty-fifth edition, Supplement, October 2006.

69. World Health Organization (2010). Healthy workplaces: a model for action: for employers, workers, policy-makers and practitioners

70. Wyatt, K. M., Brand, S., Ashby-Pepper, J., Abraham, J. \& Fleming, L. E. (2015). Understanding how healthy workplaces are created: implications for developing a national health service healthy workplace program. International journal of health services, 45(1), 161-185

71. Zhu, X., Yoshikawa, A., Qiu, L., Lu, Z., Lee, C. \& Ory, M. (2020). Healthy workplaces, active employees: a systematic literature review on impacts of workplace environments on employees' physical activity and sedentary behavior. Building and Environment, 168, 106455

72. https://www.cdc.gov/workplacehealthpromotion/model/index.html retrieved 05/06/2021

73. https://www.who.int/occupational_health/healthy_workplace_framew ork.pdf retrieved 21/07/2021 